
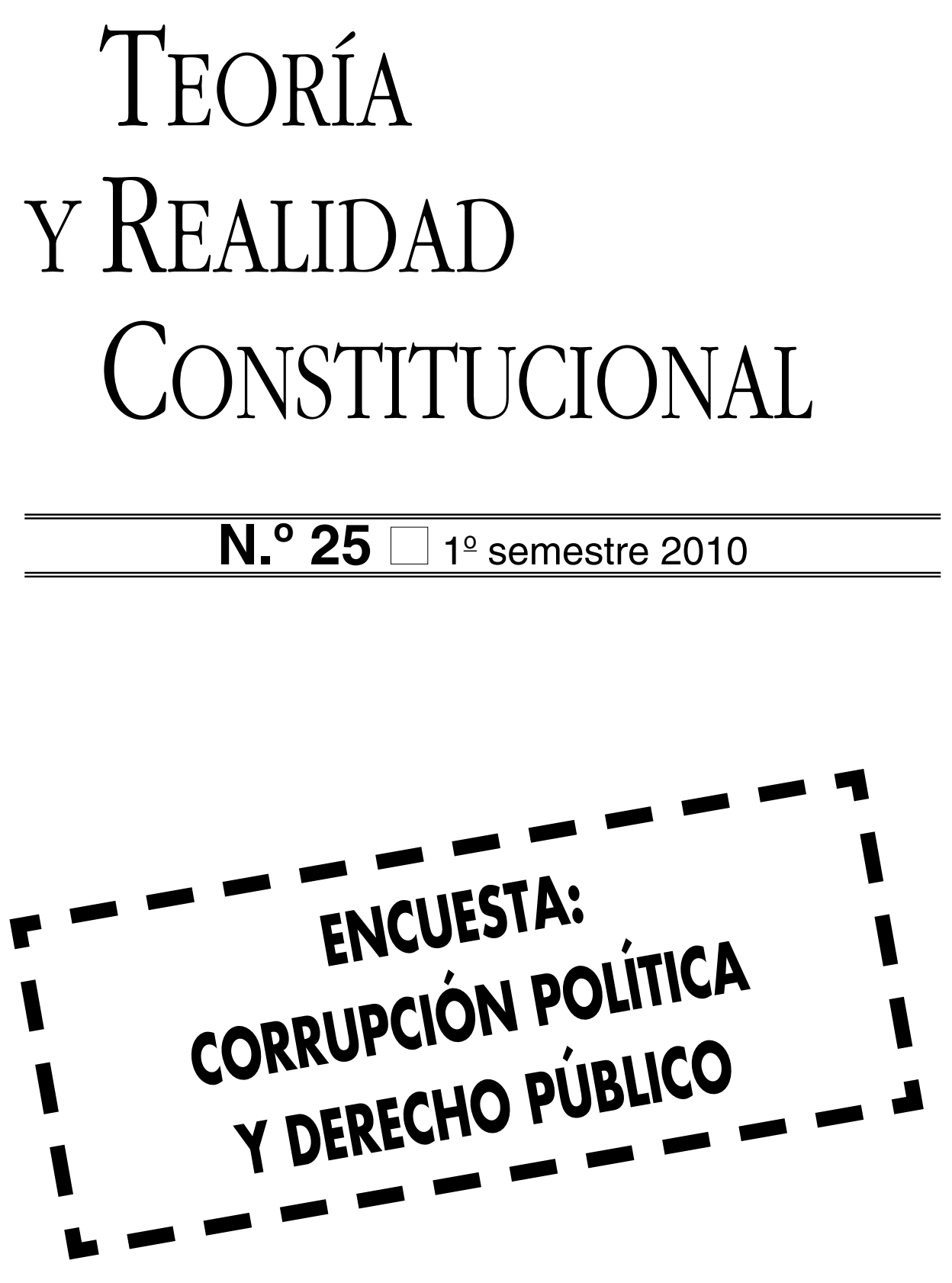


\title{
INTERVENCIONES TELEFÓNICAS Y POSTALES (EXAMEN DE LA JURISPRUDENCIA CONSTITUCIONAL)
}

\author{
MANUEL ARAGÓN REYES \\ Catedrático de Derecho Constitucional \\ Universidad Autónoma de Madrid \\ Magistrado del Tribunal Constitucional
}

SUMARIO

I. El derecho al secreto de las comunicaciones. Consideraciones generales. Papel del Tribunal Constitucional y obligación del legislador.

II. Protección constitucional del derecho al secreto de las comunicaciones.

III. Principio de legalidad: la doctrina del Tribunal Constitucional suple las deficiencias de la regulación legal (art. 579 LECrim).

IV. No hay lesión del derecho al secreto de las comunicaciones cuando la conversación telefónica es grabada por el interlocutor, ni cuando uno de los interlocutores autoriza expresamente a la autoridad policial a registrar sus llamadas para poder determinar el número de teléfono desde el que le llaman.

V. La autorización judicial de intervención de las comunicaciones ha de ser motivada y respetar los principios de legalidad y proporcionalidad.

* Parte del presente texto se corresponde con el de la conferencia pronunciada en el marco de los Cursos de Verano de la Fiscalía General del Estado, en el Pazo de Mariñán el 13 de junio de 2008. 
VI. Autorización judicial de intervenciones telefónicas en "diligencias indeterminadas".

VII. Control judicial de la intervención de la comunicación y derecho a un proceso con todas las garantías.

VIII. Pruebas ilícitamente obtenidas por vulneración del derecho al secreto de las comunicaciones y conexión de antijuridicidad.

IX. Secreto de las comunicaciones postales.

X. Derecho al secreto de las comunicaciones en el ámbito penitenciario.

XI. Tipificación penal de la vulneración del secreto de las comunicaciones.

\section{EL DERECHO AL SECRETO DE LAS COMUNICACIONES. CONSIDERACIONES GENERALES. PAPEL DEL TRIBUNAL CONSTITUCIONAL Y OBLIGACIÓN DEL LEGISLADOR}

Como es bien sabido, la principal característica que en nuestro ordenamiento tiene este derecho (garantizado por el art. 18.3 CE) es su carácter de fundamental, y, como tal (art. $53.1 \mathrm{CE}$ ): a) aplicable por todos los poderes públicos (pues les "vincula"), entre ellos, destacadamente, por los jueces y tribunales (a los que puede acudirse demandado su tutela, art. 24,1 CE) en cualquier proceso de que conozcan; b) reservada a la ley la regulación de su ejercicio; c) pero garantizándose su indisponibilidad por el legislador, en cuanto que éste, sin perjuicio de su capacidad de regulación (en la que puede moverse con un moderado grado de libertad, STC 11/1981), habrá de preservar en todo caso el "contenido esencial" del derecho. Estas tres cualidades (aplicabilidad inmediata por los órganos judiciales, reserva de ley, contenido esencial asegurado frente al legislador, esto es, frente a las mayorías parlamentarias) expresadas en el art. 53.1 CE son las que configuran, pues, a este derecho como fundamental.

A ellas se añaden otras notas, de las que sólo disfrutan, junto con éste, algunos derechos fundamentales, en cuanto que no son distintivas de la categoría genérica de derecho fundamental, sino propias únicamente de aquellos a los que la Constitución decidió otorgarles, añadidamente, una superior protección: la reserva a la ley orgánica de la regulación de su desarrollo (art. 81.1 CE), la posibilidad de acudir, frente a sus hipotéticas vulneraciones, aparte de a la tutela general judicial por los procedimientos ordinarios, a la específica tutela judicial por un procedimiento preferente y sumario (art. 53.2 CE), y, por último, el acceso al Tribunal Constitucional a través del recurso de amparo [arts. 53.2 y 161.1.b) CE], configurado éste (por la LOTC) como un remedio subsidiario a la vía judicial (que por ello ha de ser previa salvo en el supuesto que prevé el art. 42 LOTC ) y hoy, después de la reforma de la 
LOTC por la LO 6/2007, de 24 de mayo, como un instrumento de protección objetiva de derechos y no ya como una tutela subjetiva de los mismos: del "amparo tutela" (vigente hasta la última reforma de la LOTC) se ha pasado, así, a un "amparo-control".

Estas son, pues, las características del derecho al secreto de las comunicaciones garantizado por el art. 18.3 CE: ser un derecho fundamental que, además, goza de una reforzada protección. Por lo demás, en cuanto que este derecho coincide con uno de los derechos garantizados (en su art. 8) por el Convenio Europeo para la protección de los Derechos Humanos y las Libertades Fundamentales, la interpretación de nuestro derecho fundamental ha de efectuarse de conformidad con lo que aquel Convenio dispone (art. 10.2 CE), según la jurisprudencia del Tribunal Europeo de Derechos Humanos recaída sobre el mismo. Agotadas las vías internas de protección, puede acudirse también, al ser un derecho del Convenio, al recurso pertinente ante dicho Tribunal.

Por lo que se refiere a la titularidad del derecho ésta recae en cualquier persona física o jurídica, nacional o extranjera. Una amplitud de titularidades que, de un lado, se deriva de la estrecha vinculación de ese derecho con la dignidad de la persona y, de otro, se corresponde con el contenido formal del propio derecho, no ligado necesariamente a la intimidad ${ }^{1}$. Dicho contenido formal queda bien reflejado en la STC 114/1984 (FJ 7): "... el concepto de "secreto" en el art. 18.3 tiene un carácter "formal", en el sentido de que se predica de lo comunicado sea cual sea su contenido y pertenezca o no el objeto de la comunicación misma al ámbito de lo personal, lo íntimo o lo reservado". Y tal secreto cubre la comunicación realizada por cualquier medio, ya sean los explícitamente señalados por el art. 18.3 CE (postales, telegráficos o telefónicos) u otros medios más modernos de comunicación como el correo electrónico, o similares, siempre que, en estos casos, no se trate de comunicaciones abiertas.

Ahora bien, el propio art. 18.3 CE prevé el levantamiento del secreto mediante resolución judicial. Y aquí, en las intervenciones judiciales de las comunicaciones (muy especialmente de las telefónicas, aunque no sólo de ellas), es donde se han producido los problemas más complejos, que ponen en relación, de un lado, la previsión legal (más concretamente la regulación contenida en la Ley de Enjuiciamiento Criminal) y, de otro, la interpretación jurisprudencial del derecho efectuada por el Tribunal Constitucional y el Tribunal Europeo de Derechos Humanos. A dichas intervenciones está dedicado el presente trabajo, que, por ello, no pretende (sería imposible) realizar un estudio general de este derecho, sino, más limitadamente, destacar los aspectos

1 J. JIMÉNEZ CAMPO, "La garantía constitucional del secreto de las comunicaciones", Revista Española de Derecho Constitucional, no 20, mayo-agosto 1987. También, de manera general, A. Elvira Perales, "Derecho al secreto de las comunicaciones", Madrid, 2007; así como F.J. MATÍA PORTILLA, "Legislador, derechos fundamentales y proceso (comentarios a la STC 49/1999, de 5 de abril)", Revista Española de Derecho Constitucional, n 58, enero-abril, 2000. 
más relevantes de su garantía constitucional, en especial de los requisitos de aquellas intervenciones al hilo de la doctrina del Tribunal Constitucional ${ }^{2}$.

Como podrá observarse, lo que sigue es una recopilación, o más exactamente, una antología de la jurisprudencia constitucional sobre la materia que acaba de señalarse. He preferido no acompañarla de una glosa de esa doctrina y, en tal sentido, se trata de un trabajo de mera descripción. No obstante, creo que, al menos, debo subrayar aquí, de entrada, un aspecto de la misma de especial importancia teórica y práctica. Me refiero a la decisión del Tribunal Constitucional de suplir, con su doctrina, las deficiencias de la regulación legal. Esta actuación del Tribunal como legislador positivo para remediar la omisión (más exactamente la insuficiencia) de la regulación legal resultaba, a mi juicio, obligada, puesto que era la única forma de proteger el derecho fundamental, lo que no se hubiera logrado con la simple declaración de la inconstitucionalidad por omisión. Las reflexiones que, ante ello, deben hacerse, relativas a la capacidad "normadora" del Tribunal Constitucional, adquieren, sin duda, un gran interés, teórico y práctico, como antes dije, aunque me abstenga ahora de formularlas, salvo una consideración muy concreta: la llamada al legislador para, por fin, después de tanto retraso en acomodarse a las indicaciones del Tribunal Europeo de Derecho Humanos y del Tribunal Constitucional, complete la regulación legal y así deje de estar en vigor esa

2 Para mayor desarrollo me remito, aparte de a los trabajos ya citados, a los siguientes. BORRAJO INIESTA, I., "Intervención telefónica: las conversaciones por error con la policía deben ser controladas judicialmente", Tribunales de Justicia, n 6, 1997, e "Intervenciones telefónicas: síntesis jurisprudencial (en el caso de la heroína turca)", Tribunales de Justicia, n 7, 1997. CATALÁ I BAS, ALEXANDRE H., "La problemática adecuación de la legislación española sobre escuchas telefónicas a las exigencias del Convenio Europeo de Derechos Humanos y sus consecuencias", Revista del Poder Judicial. No 66, 2002. Cuesta Pastor, Pablo José, "Pruebas ilícitas: Excepciones con relación al delito de posesión de estupefacientes (A propósito de las SSTC 161 y 166, de 27 de septiembre de 1999)", Revista General de Derecho.- n. 668, 2000. FERNÁNDEZ RODRÍGUEZ, J.J, "Secreto e intervención de las comunicaciones en Internet", Civitas, 2004. GIMENO SENDRA, V., "Las Intervenciones telefónicas en la jurisprudencia del Tribunal Constitucional y del Tribunal Supremo", La Ley, T.2, 1996. Gómez Colomer, Juan Luis, "La intervención judicial de las comunicaciones telefónicas a la luz de la jurisprudencia", Revista Jurídica de Catalunya, n 1, 1998. GÓMEZ ORFANEL, G., "Domicilios y escuchas. La reforma constitucional alemana de 1998", Cuadernos de Derecho Público, n 3, 1998. MAGRO SERVET, V., "La necesaria nueva regulación de las intervenciones telefónicas a raíz de la jurisprudencia del TEDH, TC y TS", La Ley. T.5, 2004. Martínez Escamilla, Margarita, "La suspensión e intervención de las comunicaciones del preso: un análisis constitucional del artículo 51 de la ley orgánica general penitenciaria", Tecnos, Madrid, 2000. MONTERO AROCA, J, "Detención y apertura de la correspondencia y de los paquetes postales en el proceso penal", Tirant lo Blanch, 2000. MORENO CATENA, V, "La intervención de las comunicaciones en el proceso penal", La reforma de la justicia penal (estudios en homenaje al Profesor Klaus Tiedemann)", Castelló de la Plana: Col-lecció Estudis jurídics. MUÑOZ DE MORALES ROMERO, M, "Hacia la cobertura legal de las intervenciones telefónicas en el ordenamiento jurídico español: la reforma del art. 579 LECrim", Boletín de la Facultad de Derecho n.27, 2005. Narvaez Rodríguez, Antonio, "Intervenciones telefónicas: cometarios a la STC 49/1999, de 5 de abril", Repertorio Aranzadi del Tribunal Constitucional T.II 1999. RIVES SEVA, A.P., "La intervención de las comunicaciones en la jurisprudencia penal", Aranzadi, 2000. RODRÍGUEZ RUIZ, B., "El coste de los derechos fundamentales. Un comentario de la STC 49/1999, de 5 de abril”, Teoría y Realidad Constitucional, n 3, 1999. 
"normación" complementaria del Tribunal Constitucional, que sólo estaba destinado a sustituir, transitoriamente, el vacío que aquel legislador había dejado. La excepcionalidad puede ser en algún caso necesaria (en éste, por ejemplo) pero no debe prolongarse mucho, pues la normalidad (lo que la Constitución exige como normal) impone que sea el legislador (de ahí su responsabilidad) el que desarrolle, para dotarles de plena eficacia, los derechos fundamentales.

\section{PROTECCIÓN CONSTITUCIONAL DEL DERECHO AL SECRETO DE LAS COMUNICACIONES}

a) La STC 114/1984, de 29 de noviembre, FJ 7, declaró que el derecho al secreto de las comunicaciones "consagra la libertad de las comunicaciones, implícitamente, y, de modo expreso, su secreto, estableciendo en este último sentido la interdicción de la interceptación o del conocimiento antijurídico de las comunicaciones ajenas. El bien constitucionalmente protegido es así -a través de la imposición a todos del "secreto" - la libertad de las comunicaciones, siendo cierto que el derecho puede conculcarse tanto por la interceptación en sentido estricto (que suponga aprehensión física del soporte del mensaje - con conocimiento o no del mismo- o captación, de otra forma, del proceso de comunicación) como por el simple conocimiento antijurídico de lo comunicado (apertura de la correspondencia ajena guardada por su destinatario, por ejemplo). [...] Y puede también decirse que el concepto de "secreto", que aparece en el artículo 18.3, no cubre sólo el contenido de la comunicación, sino también, en su caso, otros aspectos de la misma, como, por ejemplo, la identidad subjetiva de los interlocutores o de los corresponsales. [...].Sea cual sea el ámbito objetivo del concepto de "comunicación", la norma constitucional se dirige inequívocamente a garantizar su impenetrabilidad por terceros (públicos o privados: el derecho posee eficacia erga omnes) ajenos a la comunicación misma. La presencia de un elemento ajeno a aquéllos entre los que media el proceso de comunicación, es indispensable para configurar el ilícito constitucional aquí perfilado".

b) Esta doctrina se reitera en SSTC 34/1996, de 11 de marzo, FJ 4; 70/2002, de 3 de abril, FJ 9; 123/2002, de 20 de mayo, FFJ 3 y 4; 56/2003, de 24 de marzo, FJ 2, por todas. En la STC 70/2002 se advierte que "los avances tecnológicos que en los últimos tiempos se han producido en el ámbito de las telecomunicaciones, especialmente en conexión con el uso de la informática, hacen necesario un nuevo entendimiento del concepto de comunicación y del objeto de protección del derecho fundamental, que extienda la protección a esos nuevos ámbitos, como se deriva necesariamente del tenor literal del art. 18.3 CE".

c) "La vulneración del derecho al secreto de las comunicaciones telefónicas requiere la interferencia directa en el proceso de comunicación (mutatis mutandis respecto de las comunicaciones postales STC 70/2002) mediante 
el empleo de cualquier artificio técnico de captación, sintonización o desvío y recepción de la señal telefónica como forma de acceso a los datos confidenciales de la comunicación" (SSTC 123/2002, de 20 de mayo, FJ 5 y 56/2003, de 24 de marzo, FJ 3). En consecuencia, no existe lesión del derecho al secreto de las comunicaciones cuando "la audición de la conversación se produce de modo directo [por un tercero ajeno a los interlocutores], sin intervención técnica alguna" (ATC 15/2004, de 20 de enero, FJ 4, que analiza un asunto en el que un policía, al aproximarse a una cabina telefónica, escuchó a la recurrente anunciar la colocación de dos artefactos explosivos en la oficina de correos en la que trabajaba).

d) STC 123/2002, de 20 de mayo, FJ 6 (entrega por las compañías telefónicas a la policía de los listados de llamadas): «la entrega de los listados por las compañías telefónicas a la policía sin consentimiento del titular del teléfono requiere resolución judicial, pues la forma de obtención de los datos que figuran en los citados listados supone una interferencia en el proceso de comunicación que está comprendida en el derecho al secreto de las comunicaciones telefónicas del art. 18.3 CE. [...] Ahora bien, aunque el acceso y registro de los datos que figuran en los listados constituye una forma de afectación del objeto de protección del derecho al secreto de las comunicaciones, no puede desconocerse la menor intensidad de la injerencia en el citado derecho fundamental que esta forma de afectación representa en relación con la que materializan las "escuchas telefónicas", siendo este dato especialmente significativo en orden a la ponderación de su proporcionalidad. Doctrina que se reitera en STC 56/2003, de 24 de marzo, FJ 3.

\section{PRINCIPIO DE LEGALIDAD: LA DOCTRINA DEL TRIBUNAL CONSTITUCIONAL SUPLE LAS DEFICIENCIAS DE LA REGULACIÓN LEGAL (ART. 579 LECRIM).}

a) La STC 49/1999, de 5 de abril (Pleno), señala que la literalidad del art. 18.3 CE ("se garantiza el secreto de las comunicaciones y, en especial, las postales, telegráficas y telefónicas, salvo resolución judicial") "puede inducir a pensar que la única garantía que establece inmediatamente la Constitución, en materia de intervenciones telefónicas, es la exigencia de autorización judicial. Sin embargo, un análisis más detenido de la cuestión pondrá de manifiesto que eso no es asín (FJ 3).

"En efecto, ha de destacarse en primer término que, por mandato expreso de la Constitución, toda injerencia estatal en el ámbito de los derechos fundamentales y las libertades públicas, ora incida directamente sobre su desarrollo (art. 81.1 CE), o limite o condicione su ejercicio (art. 53.1 CE), precisa una habilitación legal. Esa reserva de ley a que, con carácter general, somete la Constitución española la regulación de los derechos fundamentales y libertades públicas reconocidos en su Título I, desempeña una doble función, a saber: de una parte, asegura que los derechos que la Constitución atribuye 
a los ciudadanos no se vean afectados por ninguna injerencia estatal no autorizada por sus representantes; y, de otra, en un ordenamiento jurídico como el nuestro en el que los Jueces y Magistrados se hallan sometidos "únicamente al imperio de la Ley" y no existe, en puridad, la vinculación al precedente (SSTC 8/1981, 34/1995, 47/1995 y 96/1996) constituye, en definitiva, el único modo efectivo de garantizar las exigencias de seguridad jurídica en el ámbito de los derechos fundamentales y las libertades públicas. Por eso, en lo que a nuestro ordenamiento se refiere, hemos caracterizado la seguridad jurídica como una suma de legalidad y certeza del Derecho (STC 27/1981, FJ 10).

Esa doble función de la reserva de ley constituye, en el caso del derecho al secreto de las comunicaciones telefónicas, una doble perspectiva de análisis. Desde el primer punto de vista, es decir, desde la exigencia de que una norma legal habilite la injerencia, parece difícil negar que la propia Constitución contiene tal habilitación: desde esta perspectiva, los Jueces y Tribunales pueden, pues, acordarla, cuando concurran los presupuestos materiales pertinentes (STC 22/1984, FJ 3).

Sin embargo, desde las exigencias de certeza que han de presidir cualquier injerencia en un derecho fundamental, es también patente que el art. 18.3 CE, al no hacer referencia alguna a los presupuestos y condiciones de la intervención telefónica, resulta insuficiente para determinar si la decisión judicial es o no el fruto previsible de la razonable aplicación de lo decidido por el legislador (SSTC 131/1997, FJ 7 y 151/1997, FJ 4)". (FJ 4).

[...] No obstante "si, pese a la inexistencia de una ley que satisficiera las genéricas exigencias constitucionales de seguridad jurídica, los órganos judiciales, a los que el art. 18.3 de la Constitución se remite, hubieran actuado en el marco de la investigación de una infracción grave, para la que de modo patente hubiera sido necesaria, adecuada y proporcionada la intervención telefónica y la hubiesen acordado respecto de personas presuntamente implicadas en el mismo, respetando, además, las exigencias constitucionales dimanantes del principio de proporcionalidad, no cabría entender que el Juez hubiese vulnerado, por la sola ausencia de dicha ley, el derecho al secreto de las comunicaciones telefónicas" (FJ 5).

La STC 49/1999, de 5 de abril recoge la doctrina del TEDH sentada en la Sentencia de 30 de julio de 1998, caso Valenzuela Contreras contra España, sobre las exigencias mínimas relativas al contenido o "calidad" de la ley, y que señaló que el art. 579 LECrim (en su redacción anterior a la reforma operada por la Ley Orgánica 4/1988, de 25 de mayo), no cumple con las exigencias requeridas por el art. $8 \mathrm{CEDH}$ relativas a la previsión legal de la injerencia consistente en la intervención de las comunicaciones telefónicas.

b) La anterior doctrina sobre la previsión legal de la injerencia consistente en la intervención de las comunicaciones telefónicas se reitera en STC 184/2003, de 23 de octubre, que recoge la doctrina sentada en la Sentencia del TEDH de 18 de febrero de 2003, asunto Prado Bugallo c. España, que vuelve a declarar la vulneración del art. $8 \mathrm{CEDH}$ porque el actual art. 579 LE- 
Crim, reformado por la Ley Orgánica 4/1988, de 25 de mayo, sigue sin cumplir con las exigencias requeridas por dicho precepto relativas a la previsión legal de la injerencia. Pero la STC 184/2003, FJ 7, razona que no puede afirmarse, en el momento actual, que el Derecho interno no respete las exigencias derivadas del art. $8 \mathrm{CEDH}$, sino que a este Tribunal Constitucional le corresponde suplir las insuficiencias apreciadas en el precepto legal citado hasta que se produzca la necesaria intervención del legislador, como así viene haciendo desde la unificación y consolidación de su doctrina por la STC 49/1999, doctrina que es aplicable a los terceros y vincula a todos los órganos de la jurisdicción ordinaria. Por ello, la STC 184/2003, FJ 9, reitera que las deficiencias de la regulación legal no determinan la vulneración del art. 18.3 CE por las resoluciones judiciales que acuerdan la intervención telefónica, si el órgano judicial ha actuado en el marco de la investigación de una infracción grave, para la que de modo patente hubiera sido necesaria, adecuada y proporcionada la intervención telefónica y la hubiese acordado respecto de personas presuntamente implicadas en el mismo, respetando, además, las exigencias constitucionales dimanantes del principio de proporcionalidad.

Asimismo se reitera la doctrina citada en STC 26/2006, de 30 de enero, FJ 5.

\section{NO HAY LESIÓN DEL DERECHO AL SECRETO DE LAS COMUNICACIONES CUANDO LA CONVERSACIÓN TELEFÓNICA ES GRABADA POR EL INTERLOCUTOR, NI CUANDO UNO DE LOS INTERLOCUTORES AUTORIZA EXPRESAMENTE A LA AUTORIDAD POLICIAL A REGISTRAR SUS LLAMADAS PARA PODER DETERMINAR EL NÚMERO DE TELÉFONO DESDE EL QUE LE LLAMAN}

a) La ya citada STC 114/1984, de 29 de noviembre, declaró también (FJ 7) que «el derecho al secreto de las comunicaciones no puede oponerse, sin quebrar su sentido constitucional, frente a quien tomó parte en la comunicación misma. ... No hay "secreto" para aquél a quien la comunicación se dirige, ni implica contravención de lo dispuesto en el art. 18.3 CE la retención, por cualquier medio, como la grabación, del contenido del mensaje. ... Quien entrega a otro la carta recibida o quien emplea durante su conversación telefónica un aparato amplificador de la voz que permite captar aquella conversación a otras personas presentes no está violando el secreto de las comunicaciones, sin perjuicio de que éstas mismas conductas, en el caso de que lo así transmitido a otros entrase en la esfera "íntima" del interlocutor, pudiesen constituir atentados al derecho garantizado en el art. 18.1 CE" - lo que en el caso enjuiciado se descarta-. Partiendo de esta doctrina, la STC 114/1984 denegó el amparo solicitado por el redactor de un periódico que fue 
despedido, utilizándose como (única) prueba en su contra en el proceso por despido la grabación de una conversación telefónica que mantuvo con su jefe (al no existir lesión del derecho al secreto de las comunicaciones no cabe hablar de prueba ilícitamente obtenida).

b) Esta doctrina se reitera en ocasiones posteriores: por todas, STC 56/2003, de 24 de marzo, FJ 3, que, en aplicación de la misma, rechaza que exista lesión del derecho al secreto de las comunicaciones en el supuesto de que el registro de llamadas es intervenido con el consentimiento de uno de los titulares. Por ello, la STC 230/2007, de 5 de noviembre, FJ 2, sí declara vulnerado el citado derecho porque los agentes de la Guardia Civil accedieron al registro de llamadas memorizado en el teléfono móvil hallado en posesión del recurrente, sin contar con su consentimiento ni con la debida autorización judicial, confeccionando un listado de llamadas recibidas, enviadas y perdidas.

\section{LA AUTORIZACIÓN JUDICIAL DE INTERVENCIÓN DE LAS COMUNICACIONES HA DE SER MOTIVADA Y RESPETAR LOS PRINCIPIOS DE LEGALIDAD Y PROPORCIONALIDAD}

\section{V.1. DOCTRINA GENERAL}

a) La STC 85/1994, de 14 de marzo, FJ 3, recuerda que «el Tribunal Europeo de Derechos Humanos ha venido exigiendo toda una serie de requisitos para estimar conforme a Derecho la interceptación de las comunicaciones telefónicas de un particular. Con cita expresa de las Sentencias de dicho Tribunal de 6 de septiembre de 1978 y 2 de agosto de 1984 —respectivamente dictadas en los asuntos "Klass y otros" y "Malone»-, este Tribunal ha declarado en el ATC 344/1990, que siendo cierto que la observación de las telecomunicaciones supone una grave injerencia en la esfera de la intimidad personal constitucionalmente reconocida, como tal injerencia ha de estar sometida al principio de legalidad y, en especial, al de proporcionalidad (STC 37/1989), el cual se refiere no sólo a la relativa gravedad de la infracción punible para justificar la naturaleza de la medida, sino también a las garantías exigibles de autorización judicial específica y razonada y de respeto en su realización de requisitos similares a los existentes en otro tipo de control de comunicaciones".

b) La STC 86/1995, de 6 de junio, FJ 3, señala que "El derecho al secreto de las comunicaciones sólo puede ser limitado mediante una resolución judicial suficientemente motivada. La existencia de un mandamiento judicial autorizando la intervención, junto con la estricta observancia del principio de proporcionalidad en la ejecución de esta diligencia de investigación, constituyen exigencias constitucionalmente inexcusables que afectan al núcleo esencial del derecho al secreto de las comunicaciones, de tal modo que la ausencia de autorización judicial o la falta de motivación determinan, irremediablemente, la lesión del derecho constitucional y, por lo tanto, la prohibi- 
ción de valoración de cualquier elemento probatorio que pretenda deducirse del contenido de las conversaciones intervenidas, no sólo del resultado mismo de la intervención, sino de cualquier otra prueba derivada de la observación telefónica, siempre que exista una conexión causal entre ambos resultados probatorios".

c) Esta doctrina se reitera en SSTC 181/1995, de 11 de diciembre; 49/1996, de 26 de marzo; 54/1996, de 26 de marzo; 123/1997, de 1 de julio; 49/1999, de 5 de abril; 166/1999, de 27 de septiembre; 171/1999, de 27 de septiembre; 236/1999, de 20 de diciembre; 126/2000, de 16 de mayo; 14/2001, de 29 de enero; 202/2001, de 15 de octubre; 82/2002, de 22 de abril; $167 / 2002$, de 18 de septiembre; 184/2003, de 23 de octubre; 205/2005, de 18 de julio; 259/2005, de 24 de octubre; 104/2006, de 3 de abril; 239/2006, de 17 de julio, entre otras muchas.

d) Como recuerda la STC (Pleno) 49/1999, de 5 de abril, "La expresión del presupuesto habilitante de la intervención telefónica constituye una exigencia del juicio de proporcionalidad. Pues, de una parte, mal puede estimarse realizado ese juicio, en el momento de adopción de la medida, si no se manifiesta, al menos, que concurre efectivamente el presupuesto que la legitima. Y, de otra, sólo a través de esa expresión, podrá comprobarse ulteriormente la idoneidad y necesidad (en definitiva, la razonabilidad) de la medida limitativa del derecho fundamental". [FJ 7]

"Será preciso, por tanto, examinar si efectivamente en el momento de pedirla y acordarla, se pusieron de manifiesto ante el Juez, a través de la solicitud policial, no meras suposiciones o conjeturas de que el delito pudiera estarse cometiendo o llegar a cometerse y de que las conversaciones que se mantuvieran a través de la línea telefónica indicada eran medio útil de averiguación del delito, sino datos objetivos que permitieran pensar que dicha línea era utilizada por las personas sospechosas de su comisión o por quienes con ellas se relacionaban, y que, por lo tanto, no se trataba de una investigación meramente prospectiva. En otras palabras, el secreto de las comunicaciones no puede ser desvelado para satisfacer la necesidad genérica de prevenir o descubrir delitos (Caso Klass, núm. 51), o para despejar las sospechas sin base objetiva que surjan en la mente de los encargados de la investigación penal, por más legítima que sea esta aspiración, pues de otro modo se desvanecería la garantía constitucional" (FJ 8): no cabe, pues, acordar la intervención de las comunicaciones telefónicas como una medida prospectiva (doctrina que se reitera, entre otras muchas, en SSTC 166/1999, de 27 de septiembre, FJ 8; 171/1999, de 27 de septiembre, FJ 8; 202/2001, de 15 de octubre, FJ 4; 167/2002, de 18 de septiembre, FJ 2; 184/2003, de 23 de octubre, FJ $11 ; 165 / 2005$, de 20 de junio, FJ 4; 259/2005, de 24 de octubre, FJ 2; y 239/2006, de 17 de julio, FJ 2, por todas).

e) Como recuerda la STC 236/1999, de 20 de diciembre, FJ 3, resumiendo doctrina precedente, "la motivación de cada autorización judicial, tanto si ordena la intervención como si, en su caso, acuerda su prórroga, debe mencionar expresamente como fundamento los hechos investigados y las razones 
de hecho y jurídicas que apoyan la necesidad de hacerla, así como determinar con precisión su objeto (especialmente, la línea o líneas telefónicas intervenidas, las personas cuyas conversaciones han de ser interceptadas, la duración de la medida y quién y cómo ha de llevarse a cabo)".

f) La intervención de los listados telefónicos requiere también autorización judicial, pero la menor intensidad de la injerencia en el derecho al secreto de las comunicaciones que esta forma de afectación representa en relación con la que materializan las "escuchas telefónicas", atenúa las exigencias en cuanto a la ponderación de la proporcionalidad (STC 123/2002, de 20 de mayo, FJ 6).

\section{V.2. LA EXIGENCIA DE MOTIVACIÓN Y PROPORCIONALIDAD SE EXTIENDE} A LAS EVENTUALES PRÓRROGAS DE LA MEDIDA.

a) Como recuerda la citada STC (Pleno) 49/1999, de 5 de abril, FJ 11, "la justificación exigida para limitar el derecho al secreto de las comunicaciones ha de ser observada también "en todas aquellas resoluciones en las que se acuerde la continuación o modificación de la limitación del ejercicio del derecho, expresándose en todo momento las razones que llevan al órgano judicial a estimar procedente lo acordado", ya que "la motivación ha de atender a las circunstancias concretas concurrentes en cada momento que legitiman la restricción del derecho, aun cuando sólo sea para poner de manifiesto la persistencia de las mismas razones que, en su día, determinaron la decisión, pues sólo así pueden ser conocidas y supervisadas", sin que sea suficiente una remisión tácita o presunta integración de la motivación de la prórroga por aquella que se ofreció en el momento inicial. La necesidad de control judicial de la limitación del derecho fundamental exige aquí, cuando menos, que el juez conozca los resultados de la intervención acordada para, a su vista, ratificar o alzar el medio de investigación utilizado".

b) Esta doctrina se reitera en múltiples ocasiones (SSTC 171/1999, de 27 de septiembre, FJ 8; 236/1999, de 20 de diciembre, FJ 3; 138/2001, de 18 de junio, FJ 6; 202/2001, de 15 de octubre, FJ 6; 82/2002, de 22 de abril, FJ 5; y 239/2006, de 17 de julio, FJ 4, por todas).

\section{V.3. LA MOTIVACIÓN DE LA RESOLUCiÓN JUDICIAL QUE AUTORIZA \\ LA INTERVENCIÓN DE LAS COMUNICACIONES PUEDE HACERSE POR REMISIÓN AL OFICIO POLICIAL O DE LA FISCALÍA QUE SOLICITA LA MEDIDA, SIEMPRE QUE DICHO OFICIO CONTENGA LA SUFICIENTE MOTIVACIÓN.}

a) STC 166/1999, de 27 de septiembre, FJ 7: “Una resolución autorizatoria puede estar motivada si, integrada con la solicitud policial a la que se remite, contiene los elementos necesarios a efectos de considerar satisfechas las exigencias de ponderación de la restricción de derechos fundamentales que 
la proporcionalidad de la medida conlleva (STC 200/1997, FJ 4). De manera que los Autos de intervención y prórroga, integrados con las respectivas solicitudes policiales, pueden configurar una resolución ponderada e individualizada al caso". ${ }^{3}$

b) La citada doctrina se reitera en SSTC 171/1999, de 27 de septiembre, FJ 6; 126/2000, de 16 de mayo, FJ 7; 299/2000, de 11 de diciembre, FJ 4; 138/2001, de 18 de junio, FJ 3; 202/2001, de 15 de octubre, FJ 5; 82/2002, de 22 de abril, FJ 5; 123/2002, de 20 de mayo, FJ 6; 184/2003, de 23 de octubre, FJ 9; 205/2005, de 18 de julio, FJ 3; 26/2006, de 30 de enero, FJ 6, y 136/2006, de 8 de mayo, FJ 4, por todas. Asimismo ATC 11/2007, de 15 de enero, FJ 4, por todos.

\section{V.4. El Plazo PaRA LA INTERVENCIÓN TELEFÓNICA SE COMPUTA DESDE LA RESOLUCIÓN JUDICIAL QUE LA AUTORIZA.}

a) STC 205/2005, de 18 de julio, FJ 5: «el entendimiento de que el plazo previsto en una autorización judicial que autoriza la restricción del secreto de las comunicaciones comienza a correr el día en que aquélla efectivamente se realiza compromete la seguridad jurídica y consagra una lesión en el derecho fundamental, que tiene su origen en que sobre el afectado pesa una eventual restricción que, en puridad, no tiene un alcance temporal limitado, ya que todo dependerá del momento inicial en que la intervención tenga lugar. Es asî́ posible, por ejemplo, que la restricción del derecho se produzca meses después de que fuera autorizada, o que la autorización quede conferida sin que la misma tenga lugar ni sea formalmente cancelada por parte del órgano judicial. En definitiva, la Constitución solamente permite — con excepción de las previsiones del art. $55 \mathrm{CE}$ - que el secreto de las comunicaciones pueda verse lícitamente restringido mediante resolución judicial (art. 18.3 CE), sin que la intervención de terceros pueda alterar el dies a quo determinado por aquélla".

b) La anterior doctrina se reitera en STC 26/2006, de 30 de enero, FJ 9.

\section{AUTORIZACIÓN JUDICIAL DE INTERVENCIONES TELEFÓNICAS EN "DILIGENCIAS INDETERMINADAS"}

a) No existe vulneración del derecho al secreto de las comunicaciones (art. 18.3 CE) por el mero hecho de que la autorización judicial de intervención de las comunicaciones telefónicas no se otorgase dentro de alguno de los procedimientos legalmente previstos, sino en las denominadas "diligencias indeterminadas", pues lo relevante a estos efectos es la posibilidad de control judicial

3 También la STC 49/1999, FJ 10, había admitido ya la posibilidad de que la resolución judicial autorizatoria de la medida pueda cumplir las exigencias de motivación y proporcionalidad por remisión al oficio policial de solicitud de intervención, si tal oficio cumple dichas exigencias. 
y del Ministerio Fiscal (SSTC 49/1999, de 5 de abril, FJ 6; 126/2000, de 16 de mayo, FJ 6; 165/2005, de 20 de junio, FJ 7; y 259/2005, de 24 de octubre, FJ 5).

b) Tampoco existe vulneración del derecho al secreto de las comunicaciones (art. 18.3 CE) por el hecho de que la autorización judicial de intervención de las comunicaciones telefónicas sea acordada por Juez distinto al que investiga los hechos (STC 126/2000, de 16 de mayo, FJ 5).

\section{CONTROL JUDICIAL DE LA INTERVENCIÓN DE LA COMUNICACIÓN Y DERECHO A UN PROCESO CON TODAS LAS GARANTÍAS.}

a) La STC 49/1996, de 26 de marzo, FJ 5, señala que «la ausencia de control por el Juez instructor de la ejecución de la medida de intervención telefónica provocó la vulneración del principio de proporcionalidad, en cuanto criterio de interpretación inferido de los preceptos constitucionales en juego, toda vez que, al desconocer los hechos que realmente se estaban investigando, no pudo efectuar ponderación alguna entre el sacrificio del derecho fundamental al secreto de las comunicaciones (art. 18.3 CE) que la medida de intervención telefónica suponía, y la finalidad perseguida con la misma ... lo cual, además de vulneración del derecho al secreto de las comunicaciones de los imputados, constituyó asimismo violación del derecho a un proceso con todas las garantías ex art. $24.2 \mathrm{CE}$.

b) STC 121/1998, de 15 de junio, FJ 5: «el control judicial de la ejecución de la medida se integra en el contenido esencial del derecho cuando es preciso para garantizar su corrección y proporcionalidad. Pero no existe lesión del derecho fundamental cuando las irregularidades denunciadas, por ausencia o insuficiencia del control judicial, no se realizan en la ejecución del acto limitativo sino al incorporar a las actuaciones sumariales su resultado - entrega y selección de cintas, custodia de originales o transcripción de su contenido- pues en tales casos la restricción del derecho fundamental al secreto de las comunicaciones llevada a cabo por los funcionarios policiales en los que se delegó su práctica se ha mantenido dentro de los límites de la autorización.

Cuestión distinta es ... que la defectuosa incorporación a las actuaciones de su resultado no reúna las garantías de control judicial y contradicción suficientes como para convertir la grabación de las escuchas en una prueba válida para desvirtuar la presunción de inocencia. Mas al ser tales irregularidades procesales posteriores a la adquisición del conocimiento cuya prueba funda la condena, lo conocido gracias a las escuchas puede ser introducido en el juicio oral como elemento de convicción a través de otros medios de prueba que acrediten su contenido, por ejemplo mediante las declaraciones testificales de los funcionarios policiales que escucharon las conversaciones intervenidas". Todo lo que respecta a la entrega y selección de las cintas grabadas, a las custodia de las originales y a la transcripción de su contenido no forma parte de 
las garantías derivadas del art. 18.3 CE.

c) Esta doctrina se reitera en SSTC 151/1998, de 13 de julio, FJ 4; 49/1999, de 5 de abril, FJ 13; 166/1999, de 27 de septiembre, FJ 2; 236/1999, de 20 de diciembre, FJ 4; 237/1999, de 20 de diciembre, FJ 2; 75/2000, de 27 de marzo, FJ 4; 92/2000, de 10 de abril, FJ 3; 126/2000, de 16 de mayo, FFJ 10 y 12; 202/2001, de 15 de octubre, FJ 7; 82/2002, de 22 de abril, FJ 6; 167/2002, de 18 de septiembre, FJ 5; 184/2003, de 23 de octubre, FJ 12; y 165/2005, de 20 de junio, FJ 8, entre otras).

d) Por otra parte, el control judicial de las intervenciones telefónicas no exige la directa audición por parte del Juez de todas las cintas grabadas, ya que la audición no es el único modo legítimo de control, que también puede llevarse a cabo mediante la lectura y valoración de los informes de los agentes que llevaron a cabo las escuchas autorizadas (SSTC 82/2002, de 22 de abril, FJ 5; 205/2005, de 18 de julio, FJ 4; y 26/2006, de 30 de enero, FJ 8; y ATC 225/2004, de 4 de junio, FJ 2).

e) STC 104/2006, de 3 de abril, FJ 5: «es irrelevante que en dicha intervención se descubrieran otros hechos delictivos, pues como sostuvimos en la STC 41/1998, de 24 de febrero, FJ 22, "la Constitución no exige, en modo alguno, que el funcionario que se encuentra investigando unos hechos de apariencia delictiva cierre los ojos ante los indicios de delito que se presentaren a su vista, aunque los hallados casualmente sean distintos a los hechos comprendidos en su investigación oficial, siempre que ésta no sea utilizada fraudulentamente para burlar las garantías de los derechos fundamentales"”.

\section{PRUEBAS ILÍCITAMENTE OBTENIDAS POR VULNERACIÓN DEL DERECHO AL SECRETO DE LAS COMUNICACIONES Y CONEXIÓN DE ANTIJURIDICIDAD.}

Si la intervención telefónica lesiona el derecho fundamental garantizado por el art. 18.3 CE, todo elemento probatorio que pretendiera deducirse del contenido de las conversaciones intervenidas no puede ser objeto de valoración probatoria por el órgano judicial, al tratarse de prueba ilícitamente obtenida. Mas para decidir si las resoluciones judiciales dictadas en el proceso penal han vulnerado además el derecho a la presunción de inocencia, se hace preciso examinar si, aparte de los elementos de prueba contenidos en dichas conversaciones telefónicas o inmediatamente derivados de las mismas, hubo en el proceso otras pruebas válidas de su participación en los hechos por los que el recurrente en amparo fue condenado (conexión de antijuridicidad). Si la respuesta es positiva, el Tribunal Constitucional apreciará la lesión del derecho al secreto de las comunicaciones, pero la condena se mantiene. Si la respuesta es negativa, se apreciará también la lesión del derecho a la presunción de inocencia y se anulará la sentencia condenatoria (entre otras muchas, SSTC 85/1994, de 14 de marzo; 86/1995, de 6 de junio; 181/1995, de 11 
de diciembre; 54/1996, de 26 de marzo; 81/1998, de 2 de abril; 49/1999, de 5 de abril; 166/1999, de 27 de septiembre; 171/1999, de 27 de septiembre; 238/1999, de 20 de diciembre; 50/2000, de 28 de febrero; 126/2000, de 16 de mayo; 299/2000, de 11 de diciembre; 202/2001, de 15 de octubre; 28/2002, de 11 de febrero, 167/2002, de 18 de septiembre; 205/2002, de 11 de noviembre; $184 / 2003$, de 23 de octubre; $165 / 2005$, de 20 de junio; 205/2005, de 18 de julio; 239/2006, de 17 de julio; y 230/2007, de 5 de noviembre).

\section{SECRETO DE LAS COMUNICACIONES POSTALES}

a) ATC 104/2000, de 10 de abril, FJ 2: «la apertura de un buzón de correos en modo alguno supone, por sí sola, la vulneración del derecho al secreto de las comunicaciones".

b) STC $70 / 2002$, de 3 de abril, FJ 9 (intervención de una carta, doblada en el interior de una agenda, y leída por la Guardia Civil sin autorización judicial): Se razona que no existe lesión del derecho al secreto de las comunicaciones, «... pues la supuesta carta no presentaba ninguna evidencia externa que hubiera permitido a la Guardia Civil ex ante tener la constancia objetiva de que aquello era el objeto de una comunicación postal secreta, tutelada por el art. 18.3 CE. Por el contrario, la apariencia externa del hallazgo era equívoca: unas hojas de papel dobladas en el interior de una agenda no hay por qué suponer que fueran una carta y no resultaría exigible a la Guardia Civil que actuara respecto de cualquier papel intervenido al delincuente, en el momento de la detención, con la presunción de que se trata de una comunicación postal.

A lo que ha de añadirse otra consideración, relativa al momento en que se produce la intervención policial. Pues tal intervención no interfiere un proceso de comunicación, sino que el citado proceso ya se ha consumado, lo que justifica el tratamiento del documento como tal (como efectos del delincuente que se examinan y se ponen a disposición judicial) y no en el marco del secreto de las comunicaciones. La protección del derecho al secreto de las comunicaciones alcanza al proceso de comunicación mismo, pero finalizado el proceso en que la comunicación consiste, la protección constitucional de lo recibido se realiza en su caso a través de las normas que tutelan la intimidad $\mathrm{u}$ otros derechos.

Estos dos datos (falta de constancia o evidencia ex ante de que lo intervenido es el objeto de una comunicación secreta impenetrable para terceros y falta de interferencia en un proceso de comunicación) son los decisivos en el presente supuesto para afirmar que no nos hallamos en el ámbito protegido por el derecho al secreto de las comunicaciones postales sino, en su caso, en el ámbito del derecho a la intimidad del art. $18.1 \mathrm{CE}{ }^{4}{ }^{4}$

4 La STC 70/2002 rechaza igualmente la pretendida lesión del derecho a la intimidad (art. 18.1 CE): «Ciertamente, lo intervenido por la Guardia Civil en el momento de la detención per- 
c) STC 281/2006, de 9 de octubre, FJ 3 (paquetes postales y art. 18.3 CE): "El art. 18.3 CE no alude al secreto postal sino al secreto de las comunicaciones postales [e] identifica de forma individualizada las comunicaciones postales diferenciándolas de las telegráficas. Por consiguiente, no todo envío o intercambio de objetos o señales que pueda realizarse mediante los servicios postales es una comunicación postal pues, de un lado, no se refiere al secreto postal y, de otro, también las comunicaciones telegráficas se mencionan expresamente en este precepto constitucional, siendo el servicio de telégrafos uno de los servicios prestados por los propios servicios postales. La noción constitucional de comunicación postal es, en consecuencia, una noción restringida que no incluye todo intercambio realizado mediante los servicios postales. De otra parte, ha de tenerse en cuenta que el término "comunicaciones" al que se refiere el art. 18.3 CE, sirve para denotar el objeto de protección de este derecho constitucional sea cual sea el medio a través del cual la comunicación tiene lugar — postal, telegráfico, telefónico...-; de modo que la noción constitucional de comunicación ha de incorporar los elementos o características comunes a toda clase de comunicación. [...] De otra parte, es de

tenecía al ámbito de la intimidad. Una agenda que el recurrente llevaba consigo y un documento, que no tenía sobre, pero que se encontraba en el interior de la agenda, son objetos pertenecientes al ámbito propio y reservado frente a la acción y el conocimiento de los demás, tanto desde un punto de vista objetivo (atendiendo al contenido de lo intervenido), como desde un punto de vista subjetivo (la protección otorgada al objeto por su titular, en cuanto a la preservación frente a terceros). [...] Sentado lo anterior, debemos analizar a continuación la legitimidad de la actuación policial ... En primer lugar, se trata de una diligencia practicada en el curso de la investigación de un delito y en concreto en el momento de la detención, y orientada a la averiguación del mismo y a la recogida de instrumentos, efectos y pruebas del mismo. Por tanto, concurre un fin constitucionalmente legítimo. En segundo lugar, existe habilitación legal para la actuación de la policía, como ya hemos señalado. En tercer lugar, si bien la actuación no se realiza previa autorización judicial, podemos afirmar que estamos en uno de los supuestos excepcionados de la regla general, pues existen y pueden constatarse razones para entender que la actuación de la Guardia Civil era necesaria. Los funcionarios policiales se encontraban investigando un delito de tráfico de drogas, con implicaciones internacionales y en el marco de lo que parecía una red de criminalidad organizada, lo que resulta relevante no tanto por la gravedad del hecho - que la tiene- sino sobre todo por la modalidad delictiva y la enorme dificultad de su persecución penal. La investigación había dado como resultado la detención de varios sujetos, en el curso de una entrega controlada de drogas, pero podía suponerse que había otros implicados o datos relevantes que pudieran extraerse de un primer examen de los objetos intervenidos al recurrente, lo que razonablemente hace necesaria la intervención policial inmediata, pues una eventual espera por el tiempo necesario para obtener la autorización judicial hubiera hecho probablemente inútil la intervención. Por tanto, la necesidad de intervención inmediata en el caso concreto está acreditada. A lo que ha de añadirse, por último, que la actuación policial respeta el principio de proporcionalidad, pues se trata de una medida idónea para la investigación del delito (de la agenda y de los documentos se podían extraer — como así fue- pruebas incriminatorias y nuevos datos para la investigación), imprescindible en el caso concreto (no existían otras menos gravosas) y ejecutada de modo tal que el sacrificio del derecho fundamental no resulta desmedido en relación con la gravedad de los hechos y las sospechas existentes.

De todo lo cual cabe concluir que, siendo la actuación policial constitucionalmente legítima, el sacrificio del derecho a la intimidad del recurrente está justificado por la presencia de intereses superiores constitucionalmente relevantes, no pudiendo apreciarse vulneración alguna del derecho fundamental" (FJ 10). 
señalar que los convenios internacionales sobre derechos humanos tampoco protegen el secreto de toda comunicación postal ni su inviolabilidad. [...]. Por tanto, el derecho al secreto de las comunicaciones postales sólo protege el intercambio de objetos a través de los cuales se transmiten mensajes mediante signos lingüísticos, de modo que la comunicación postal es desde la perspectiva constitucional equivalente a la correspondencia.

Varias precisiones son aún necesarias a los efectos de la delimitación de la noción constitucional de correspondencia del art. 18.3 CE. De un lado, en la medida en que los mensajes pueden expresarse no solo mediante palabras, sino a través de otro conjunto de signos o señales que componen otra clase de lenguajes, y dado que los mensajes pueden plasmarse no solo en papel escrito, sino también en otros soportes que los incorporan - cintas de cassette o de vídeo, CD's o DVD's, etc.- - la noción de correspondencia no puede quedar circunscrita a la correspondencia escrita, entendida ésta en su sentido tradicional. Por ello, se ha de estar a la delimitación que la regulación legal sobre el servicio postal universal establece, que al efecto atiende a ciertas características externas y físicas - tamaño- del objeto de envío - sobre, paquete-, en cuyo interior se introducen los soportes físicos de los mensajes - papeles, cintas, CD's ... Desde esta perspectiva, no gozan de la protección constitucional aquellos objetos — continentes - que por sus propias características no son usualmente utilizados para contener correspondencia individual sino para servir al transporte y tráfico de mercancías (ATC 395/2003, de 11 de diciembre, FJ 3), de modo que la introducción en ellos de mensajes no modificará su régimen de protección constitucional. Ni tampoco gozan de la protección constitucional del art. 18.3 CE aquellos objetos que, pudiendo contener correspondencia, sin embargo, la regulación legal prohíbe su inclusión en ellos, pues la utilización del servicio comporta la aceptación de las condiciones del mismo.

Además, si lo que se protege es el secreto de la comunicación postal quedan fuera de la protección constitucional aquellas formas de envío de la correspondencia que se configuran legalmente como comunicación abierta, esto es, no secreta. Así sucede cuando es legalmente obligatoria una declaración externa de contenido, o cuando bien su franqueo o cualquier otro signo o etiquetado externo evidencia que, como acabamos de señalar, no pueden contener correspondencia, pueden ser abiertos de oficio o sometidos a cualquier otro tipo de control para determinar su contenido.

$\mathrm{Si}$, como acabamos de recordar, el derecho fundamental protege el secreto de las comunicaciones frente a cualquier clase de interceptación en el proceso de comunicación, es indiferente el procedimiento a través del cual se acceda al conocimiento del proceso de la comunicación postal o del contenido de la correspondencia, por lo que se vulnera este derecho aún cuando a tal conocimiento no se acceda mediante la apertura del continente o de la propia carta, documento u objeto, de otro modo cerrado. La existencia de la comunicación, la identidad de los corresponsales, el momento en que se produce, los lugares de remisión y destino, son todos ellos datos que, una vez 
iniciado el proceso de comunicación, son secretos para cualquier persona ajena a la comunicación, de modo que su conocimiento por quien presta el servicio postal puede ser utilizado a los solos efectos de la prestación del servicio (mutatis mutandis, STC 123/2002, de 20 de mayo, FFJJ 5, 6).

Esta afirmación, no obstante, ha de ser matizada y ponerse en conexión con las especialidades del objeto de protección cuando de las comunicaciones postales se trata. Pues, si lo que se protege es la comunicación humana en cuanto expresión de sentido, sólo serán lesivas del derecho a la comunicación postal aquellas formas de acceso al contenido del soporte material del mensaje que supongan formas de tomar conocimiento del mensaje, por lo que no serán lesivos de este derecho aquellos procedimientos que, siendo aptos para identificar que el contenido del sobre o del soporte sea un objeto ilícito, no lo son, sin embargo, para conocer el mensaje mismo - inspecciones mediante perros adiestrados, escáneres... Por consiguiente, el procedimiento más habitual de vulneración del derecho al secreto de la correspondencia será su apertura, aunque no pueda descartarse la vulneración del derecho mediante otros procedimientos técnicos que permitan acceder al contenido del mensaje sin proceder a la apertura de la correspondencia.

Finalmente, a los efectos de la protección del derecho al secreto de las comunicaciones postales es indiferente quién presta el servicio postal, de modo que el derecho al secreto de las comunicaciones postales alcanza el proceso de comunicación tanto si se presta mediante servicios públicos como privados, dado que la Ley 24/1998, de 13 de julio, del servicio postal universal y de liberalización de los servicios postales ha procedido a su liberalización.

De esta delimitación derivan varias consecuencias. Es la primera que el envío de mercancías o el transporte de cualesquiera objetos, incluidos los que tienen como función el transporte de enseres personales - maletas, maletines, neceseres, bolsas de viaje, baúles, etc.- por las compañías que realizan el servicio postal no queda amparado por el derecho al secreto de las comunicaciones, pues su objeto no es la comunicación en el sentido constitucional del término. Es la segunda que el art. 18.3 CE no protege directamente el objeto físico, el continente o soporte del mensaje en sí, sino que éstos sólo se protegen de forma indirecta, esto es, tan sólo en la medida en que son el instrumento a través del cual se efectúa la comunicación entre dos personas - destinatario y remitente. Por consiguiente, cualquier objeto — sobre, paquete, carta, cinta, etc.- que pueda servir de instrumento o soporte de la comunicación postal no será objeto de protección del derecho reconocido en el art. 18.3 CE si en las circunstancias del caso no constituyen tal instrumento de la comunicación, o el proceso de comunicación no ha sido iniciado (STC 137/2002, de 3 de junio, FJ 3); así, no constituyen objeto de este derecho cuando se portan por su propietario o terceros ajenos a los servicios postales, o viaja con ellos, o los mantienen a su disposición durante el viaje. Estos objetos, máxime si de sus características externas se infiere su destino al transporte de enseres personales o se hace constar en su exterior su condición de 
objeto personal o íntimo, quedarán, no obstante, protegidos por el derecho a la intimidad personal (art. 18.1 CE); y, por consiguiente, de conformidad con nuestra jurisprudencia constitucional, la ley podrá autorizar a la autoridad administrativa para su apertura o para proceder a inspeccionar y controlar su contenido por cualquier procedimiento, siendo requisito de la constitucionalidad de tal control o inspección su sujeción a las máximas derivadas del principio de proporcionalidad, esto es, ser necesaria para alcanzar un fin constitucionalmente legítimo, idónea para alcanzarlo y que la concreta forma de control o inspección reporte en el caso menos sacrificios en el derecho individual que beneficios en los intereses generales.

La delimitación del ámbito de protección constitucional de las comunicaciones postales tiene en cuenta el diferente régimen jurídico de los envíos postales y de los envíos de correspondencia establecido tanto en la legislación internacional como interna".

\section{DERECHO AL SECRETO DE LAS COMUNICACIONES EN EL ÁMBITO PENITENCIARIO.}

\section{X.1. DOCTRINA GENERAL}

Los internos en un Centro Penitenciario son también titulares del derecho al secreto de las comunicaciones (art. 18.3 CE), si bien la Ley Orgánica General Penitenciaria y su Reglamento determinan los límites de su ejercicio en atención a las peculiaridades de la relación penitenciaria. Así pues, la persona recluida en un centro penitenciario goza, en principio, del derecho al secreto de las comunicaciones, aunque puede verse afectada por las limitaciones expresamente mencionadas en el art. 25.2 CE (entre otras muchas, SSTC 170/1996, de 20 de octubre, FJ 5; 128/1997, de 14 de julio, FJ 4; 175/1997, de 27 de octubre, FJ 2; 200/1997, de 24 de noviembre, FJ 2; 175/2000, de 26 de junio, FJ 3; 106/2001, de 23 de abril, FJ 6; 192/2002, de 28 de octubre, FJ 5, etc.).

\section{X.2. Distinción ENTRE COMUNICACIONES GENERALES Y ESPECÍFICAS.}

a) STC 183/1984, de 20 de junio, FJ 5 [antiguo Reglamento Penitenciario]: "Es evidente que el art. 51 de la LOGP distingue entre las comunicaciones, que podemos calificar de generales, entre el interno con determinada clase de personas —art. 51.1 - y las comunicaciones específicas que aquél tenga con su Abogado defensor o con el Abogado expresamente llamado en relación con asuntos penales (art. 51.2); la primera clase de comunicaciones viene sometida al régimen general del art. 51.5, que autoriza al Director del Centro a suspenderlas o intervenirlas "por razones de seguridad, de interés del tratamiento y del buen orden del establecimiento", según precisa el art. 51.1, 
mientras que las segundas son sometidas al régimen especial del art. 51.2, cuya justificación es necesario encontrar en las exigencias y necesidades de la instrucción penal, a las cuales es totalmente ajena la Administración Penitenciaria, que no tiene posibilidad alguna de ponderar circunstancias procesales que se producen al margen del ámbito penitenciario. [...]

Esta diferenciación esencial que existe entre el art. 51.5 —régimen general cuya única remisión válida es al art. 51.1- y el art. 51.2 pone de manifiesto la imposibilidad constitucional de interpretar este último precepto en el sentido de considerar alternativas las dos condiciones de "orden de la autoridad judicial" y "supuestos de terrorismo", que en el mismo se contienen, así como derivar de ello la legitimidad constitucional de una intervención administrativa que es totalmente incompatible con el más intenso grado de protección que la norma legal confiere al derecho de defensa en los procesos penales. Dichas condiciones habilitantes deben, por el contrario, considerarse acumulativas y, en su consecuencia, llegarse a la conclusión que el art. 51.2 de la LOGP autoriza únicamente a la autoridad judicial para suspender o intervenir, de manera motivada y proporcionada, las comunicaciones del interno con su Abogado sin que autorice en ningún caso a la Administración Penitenciaria para interferir esas comunicaciones".

b) STC 58/1998, de 16 de marzo, FJ 7: "constitucionalmente debe entenderse que el sistema de garantías reforzadas para la intervención del art. 51.2 LOGP comprende las comunicaciones escritas, del tipo que sean, entre preso y Abogado y que la alusión de dicho apartado a la "celebración en departamentos apropiados" no supone una exclusión de las comunicaciones escritas sino una mera especificación del modo en el que deben celebrarse las orales".

c) STC 106/2001, de 23 de abril, FJ 6: «El art. 51 LOGP reconoce el derecho de los reclusos a las comunicaciones, diferenciando el propio precepto, en cuanto al ejercicio de tal derecho, entre varias modalidades de comunicación, que son de muy diferente naturaleza y vienen, por ello, sometidas a regímenes legales claramente diferenciados. Por lo que se refiere a las limitaciones que pueden experimentar las denominadas comunicaciones genéricas que regulan los arts. 51.1 LOPG y concordantes RP de 1996, esto es, las que los internos pueden celebrar con sus familiares, amigos y representantes de organismos internacionales e instituciones de cooperación penitenciaria, que son las afectadas en este caso por la intervención que cuestiona el recurrente en amparo según él mismo reconoce en sus escritos, el citado art. 51.1 LOGP, además de mencionar los casos de incomunicación judicial, impone que tales comunicaciones se celebren de manera que se respete al máximo la intimidad, pero autoriza que sean restringidas por razones de seguridad, de interés del tratamiento y del buen orden del establecimiento. Por su parte, el art. 51.5 LOGP permite que tales comunicaciones sean intervenidas motivadamente por el Director del centro penitenciario, dando cuenta a la autoridad judicial competente. En suma, el citado precepto legal permite la intervención de las denominadas comunicaciones genéricas por razones de seguridad, interés del 
tratamiento y del buen orden del establecimiento, configurándose tales supuestos, por lo tanto, como causas legítimas para ordenar la intervención de las comunicaciones de un interno".

\section{X.3. Prohibición para la Administración penitenciaria de intervenir LA CORRESPONDENCIA DEL INTERNO CON EL MinisteRIO FISCAL Y CON LOS ÓRGANOS JUDICIALES}

La decisión de la Administración Penitenciaria de intervenir la correspondencia del interno dirigida al Ministerio Fiscal o a los órganos judiciales, con independencia de que el escrito se entregue para su curso en sobre abierto o cerrado, supone una clara vulneración del derecho al secreto de las comunicaciones del interno (STC 175/2000, de 26 de junio, FJ 4).

\section{X.4. Requisitos Para la INTERVENCión DE La CORRESPONDENCIA DE LOS RECLUSOS}

a) STC 170/1996, de 20 de octubre, FFJ 5 y 6: «La Ley ha conferido a la intervención de las comunicaciones un carácter excepcional, como lo demuestra el tenor literal del art. 51 LOGP, que comienza enfatizando que "los internos estarán autorizados a comunicar periódicamente». La intervención ha de ser, pues, estrictamente necesaria para la consecución de los fines que la justifican, lo que ha de plasmarse en la motivación del Acuerdo de intervención. La motivación del Acuerdo de intervención resulta un elemento imprescindible para la garantía de los derechos de los reclusos. La intervención de las comunicaciones, medida excepcional, no debe adoptarse con carácter general e indiscriminado, ni por más tiempo del que sea necesario para los fines que la justifican". Además, la medida ha de ser notificada al interno y comunicada al Juzgado de Vigilancia Penitenciaria.

b) La doctrina citada se reitera en múltiples ocasiones (entre otras, SSTC 175/1997, de 27 de octubre, FJ 4; 200/1997, de 24 de noviembre, FJ 4; 188/1999, de 25 de octubre, FJ 8; 141/1999, de 22 de julio, FFJ 5 y ss). La STC 106/2001, de 23 de abril, FJ 6, contiene un resumen sistemático de esta doctrina: "en cuanto a los requisitos que deben de cumplir los Acuerdos o medidas de intervención de las comunicaciones genéricas, junto a la exigencia de motivación y de dar cuenta a la autoridad judicial competente que impone el art. 51.5 LOGP, así como la de notificación al interno afectado que establecen los arts. 43.1 y $46.5 \mathrm{RP}$ de 1996, este Tribunal Constitucional ha añadido la necesidad de preestablecer un límite temporal a la medida de intervención". A su vez, este resumen doctrinal de la STC 106/2001 se reitera en resoluciones posteriores: SSTC 192/2002, de 28 de octubre, FJ 5; 193/2002, de 28 de octubre, FJ 3; 194/2002, de 28 de octubre, FJ 6; 169/2003, de 29 de septiembre, FJ 2. 


\section{X.5. Prohibición de utilizar COMO PRUEBA DE CARGO PARA SANCIONAR AL RECLUSO, ELEMENTOS PROBATORIOS OBTENIDOS CON VULNERACIÓN DEL DERECHO AL SECRETO DE LAS COMUNICACIONES}

La valoración como prueba de cargo para sancionar disciplinariamente al interno de elementos probatorios obtenidos como consecuencia de esa ilícita intervención de la correspondencia supone la lesión del derecho a la presunción de inocencia (art. 24.2 CE), lo que determina la nulidad del acuerdo sancionador del centro penitenciario y de las resoluciones del Juez de Vigilancia Penitenciaria que lo confirmaron (SSTC 127/1996, de 9 de julio, FJ 3; 175/200, de 26 de junio, FFJ 4 a 6; 169/2003, de 29 de septiembre, FJ 5).

\section{TIPIFICACIÓN PENAL DE LA VULNERACIÓN DEL SECRETO DE LAS COMUNICACIONES}

La STC 34/1996, de 11 de marzo, FJ 5, razona que es constitucionalmente irreprochable la decisión del legislador de "tipificar penalmente los comportamientos que atenten contra al secreto de las comunicaciones telefónicas sin distinguir el cauce tecnológico por el que se establecen, al objeto de dar la máxima protección a los derechos constitucionales al honor y a la intimidad personal (art. 18.1 CE), para cuya efectividad el secreto de las comunicaciones es un instrumento constitucionalmente previsto (art. 18.3 CE)".5

TITLE: Phone and mail interventions (An exam of constitutional jurisprudence).

ABSTRACT: This paper analyses the constitutional problems raised by the phone and mail interventions from the vantage of the protection of privacy. The legal regulation required by the Constitution has turned out to be insufficient. Therefore the main task of protection of the right has fallen on the judiciary and subsequently on the Constitutional Court. Prof. Aragon's contribution focuses on the questions und circumstances that surround this issue.

RESUMEN: El trabajo examina los problemas constitucionales que plantean las intervenciones telefónicas y postales, problema que no sólo es capital, por sí mismo, ya que está en juego el derecho del secreto de las comunicaciones y por ello los limites muy estrictos para suspenderlo o levantarlo mediante resolución judicial, sino que se agudiza entre nosotros por una muy defectuosa regulación legal de dichas intervenciones, defectos que han tenido que salvarse mediante la jurisprudencia del Tribunal Europeo de Derechos Humanos, del Tribunal Supremo y, sobre todo, del Tribunal Constitucional que aqui, y de manera inevitable, ha tenido que actuar de legislador positivo. Esos problemas, y esas circunstancias, se analizan en el trabajo, así como las condiciones y

5 La Ley Orgánica 7/1984, de 15 de octubre, introdujo en el Código Penal de 1973 el art. 497 bis, que castigaba a quien "para descubrir los secretos o la intimidad de otros interceptare sus comunicaciones telefónicas o utilizare instrumentos o artificios técnicos de escucha, transmisión, grabación o reproducción del sonido". La regulación actual, más completa, se contiene en el art. 197 del vigente Código Penal. 
limites que, en atención a casos concretos, ha tenido que ir perfilando nuestra jurisprudencia. Por todo ello, el análisis realizado, tanto en cuanto a los problemas generales como en lo que se refiere a los problemas concretos, esto es, a las condiciones precisas para la licitud de la intervención judicial de las comunicaciones, parte de la jurisprudencia constitucional sobre la materia.

Palabras Clave: Derecho al secreto de las comunicaciones. Intervención judicial de las comunicaciones telefónicas y postales. Motivación de la intervención judicial. 